\title{
Optimal Power Sharing of an Inverter-Based Autonomous Microgrid
}

\author{
M. Hassan ${ }^{1,2}$ and M. Abido ${ }^{1}$ \\ ${ }^{1}$ Electrical Engineering Department \\ King Fahd University of Petroleum \& Minerals, Dhahran, (Saudi Arabia) \\ Phone/Fax number: + 966 38607332/38603535, e-mail: mhassan@kfupm.edu.sa, mabido@kfupm.edu.sa \\ ${ }^{2}$ Electrical Engineering Department \\ Faculty of Engineering, Mansoura University, Mansoura (Egypt) \\ Phone/Fax number: + 20 1090768484, e-mail: mah_ali_ali@mans.edu.eg
}

\begin{abstract}
Stability of the autonomous microgrids while sharing the power between multiple distributed generation (DG) units is an important task. Conventional droop control is usually used for power sharing between DGs. Power sharing coefficients and controller parameters affect the stability of the microgrid. In this paper, to improve the transient dynamic response of the microgrid, a power derivative-integral term is added to the conventional droop control. The design problem is formulated as an optimization problem. The power sharing coefficients and controller parameters are obtained using the particle swarm optimization (PSO) to achieve the microgrid stability based on power error minimization. Nonlinear time domain simulation is executed to investigate the proposed controller effectiveness for different disturbances. Finally the results show satisfactory performance with efficient transient damping characteristics of the autonomous microgrid.
\end{abstract}

\section{Key words}

Microgrid, Power Sharing, Control, Optimization, PSO.

\section{Introduction}

Great much attention being paid to the impacts of increasing amount of DG units connected to the utility at the distribution level. DG is a power source connected directly to the customer side or to the distribution network [1]-[2]. DGs almost utilize power electronics converters to interface with the utility [3]. The advancement of the control techniques and increase of penetration level of DG units in the grid have generally paved the way for the DG units to be operated as a microgrid [4]-[6]. Microgrid can be basically defined as an integrating various distributed generation resources to the utility using interface power electronics to provide high quality and reliability electric power. Although microgrids can be used to supply the loads during emergencies, power shortages, and any interruption to the main grid, they faced many challenges, such as plug and play DG units, islanding detection, voltage and frequency controls, power quality, stability problems, protection and resynchronization. Microgrids operate in grid connected and autonomous modes [7]-[10]. Maintaining the voltage and frequency of the system and supporting the required active and reactive powers is the main task in the autonomous microgrid. Conventional droop control is usually used for sharing powers between DGs connecting together when it is difficult to communicate between them especially if there are located far away from each other [11]-[12]. Due to the lack of inertial of the inverter-based DG, the autonomous microgrid stability is very important to provide ride through during transients [13]. Several control techniques have been proposed to achieve accurate power sharing based on the droop method [14]-[20]. A virtual frequency-voltage control was presented to achieve accurate control and to improve the microgrid stability [14]. The frequency and voltage were transformed to virtual voltage and frequency to realize a decoupled real and reactive power control. A minimum current tracking control was given to improve the power sharing in a microgrid [15]. An improved droop controller was presented to obtain accurate power sharing [16]. The load voltage drop was reduced due to the effects of the load and the droop coefficients. An improvement of reactive power sharing was presented using $\mathrm{Q}^{-} \mathrm{V}$ method [17]. A scheme for power management of the low voltage autonomous microgrid was presented in [18]. An enhanced control strategy was given to improve the reactive power sharing accuracy [19]. High droop gains of conventional droop control were applied to stabilize the microgrid [20]. Although most of these control schemes have tried to solve the problems of voltage regulation as well as power sharing, a slow dynamic response, transient oscillations and bad controllability are the main problems face the conventional droop control [21].

The improvement of the transient response of a conventional droop controller, presented in our previous work, is still unsatisfactory [22]. In this paper, to solve this problem, a power derivative-integral term is added to the conventional droop control. Modified droop control strategy is presented to improve the performance of the existing droop methods. In fact, the transient droop parameters have to be selected carefully to guarantee stability and good transient response [21]. A novel scheme to obtain these droop coefficients is proposed to improve the transient response of inverter-based DGs of the autonomous microgrid. The nonlinear autonomous microgrid model and its control are explained. The 
problem is formulated as optimization problem where PSO is used to obtain the power sharing coefficients and controller parameters to achieve the microgrid stability. In addition, the effectiveness of the proposed method is validated using simulation results.

\section{Autonomous Microgrid Controller}

Fig. 1 shows the typical controllers of the autonomous microgrid which include power, voltage and current controllers which are used to control the output powers of these DGs as well as to maintain the voltage and frequency of this autonomous microgrid system.

\section{A. Power Controller}

Most of the inverter-based DGs use the conventional droop method to share the power between these DGs. The power controller emulates the power sharing of the synchronous generators. The conventional power controller and its concept are shown in Figs. 2\&3 respectively. Firstly, the instantaneous power is determined using the measured output voltage and measured output current. Secondly, the fundamental components of the measured real and reactive powers $P_{c}$ and $Q_{c}$ are obtained by passing them through low pass filter. Finally, the d-axis output reference voltage $v^{*}$ od and the frequency $\omega$ corresponding to these powers can be determined as follows;

$$
\begin{array}{ll}
v_{o d}^{*}=V_{n}-n_{q} Q_{c} & ,
\end{array}
$$

where $\omega_{n}$ and $V_{n}$ are the DG angular frequency and DG voltage magnitude nominal values respectively, $m_{p}$ and $n_{q}$ are the droop gains. $V^{*}$ od is setting to be aligned with $\mathrm{d}$ axis of the inverter reference frame while $v_{o q}^{*}$ is set to zero.

\section{B. Voltage Controller}

The PI voltage controller shown in Fig. 4 is used to control the DG output voltage. The state equations of the voltage controller are given as follows:

$$
\begin{aligned}
& \phi_{d}^{\bullet}=v_{o d}^{*}-v_{o d}, \phi_{q}^{\bullet}=v_{o q}^{*}-v_{o q} \\
& i_{l d}^{*}=F i_{o d}-\omega_{n} C_{f} v_{o q}+K_{p v}\left(v_{o d}^{*}-v_{o d}\right)+K_{i v} \phi_{d} \\
& i_{l q}^{*}=F i_{o q}+\omega_{n} C_{f} v_{o d}+K_{p v}\left(v_{o q}^{*}-v_{o q}\right)+K_{i v} \phi_{q}
\end{aligned}
$$

where $\mathrm{F}$ is the voltage controller Feed-forward gain.

\section{Current Controller}

The PI current controller shown in Fig. 5 is used to control the output current. The state equations along with the algebraic equations are given as:

$$
\begin{gathered}
\gamma_{d}^{\bullet}=i_{l d}^{*}-i_{l d} \quad, \gamma_{q}^{\bullet}=i_{l q}^{*}-i_{l q} \\
v_{i d}^{*}=-\omega_{n} L_{f} i_{l q}+K_{p c}\left(i_{l d}^{*}-i_{l d}\right)+K_{i c} \gamma_{d} \\
v_{i q}^{*}=\omega_{n} L_{f} i_{l d}+K_{p c}\left(i_{l q}^{*}-i_{l q}\right)+K_{i c} \gamma_{q}
\end{gathered}
$$

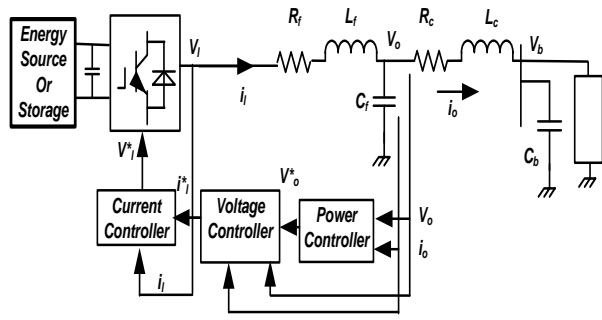

Fig. 1. Autonomous microgrid controllers

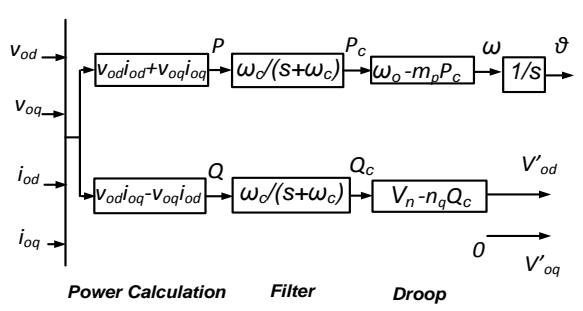

Fig. 2. Power controller

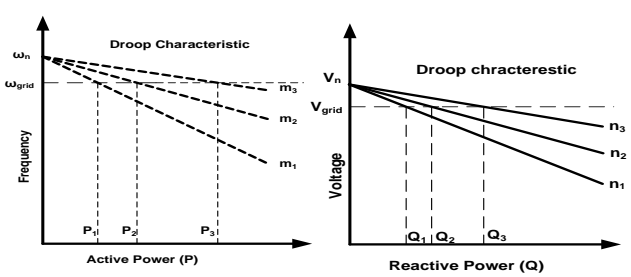

Fig. 3. Droop characteristics

\section{LC Filter and Coupling Inductance}

It is assuming that the inverter will produce the required voltage $\left(v_{i}=v_{i}^{*}\right)$. The coupling inductance and the $L C$ filter models can be described as follows:

$$
\begin{gathered}
\dot{i}_{l d}=-\frac{r_{f}}{L_{f}} i_{l d}+\omega i_{l q}+\frac{1}{L_{f}}\left(v_{i d}-v_{o d}\right) \\
\dot{i}_{l q}=-\frac{r_{f}}{L_{f}} i_{l q}-\omega i_{l d}+\frac{1}{L_{f}}\left(v_{i q}-v_{o q}\right) \\
\dot{v}_{o d}=\omega v_{o q}+\frac{1}{C_{f}}\left(i_{l d}-i_{o d}\right) \\
\dot{v}_{o q}=-\omega v_{o d}+\frac{1}{C_{f}}\left(i_{l q}-i_{o q}\right) \\
\dot{i}_{o d}=-\frac{r_{c}}{L_{c}} i_{o d}+\omega i_{o q}+\frac{1}{L_{c}}\left(v_{o d}-v_{b d}\right) \\
\dot{i}_{o q}=-\frac{r_{c}}{L_{c}} i_{o q}-\omega i_{o d}+\frac{1}{L_{c}}\left(v_{o q}-v_{b q}\right)
\end{gathered}
$$

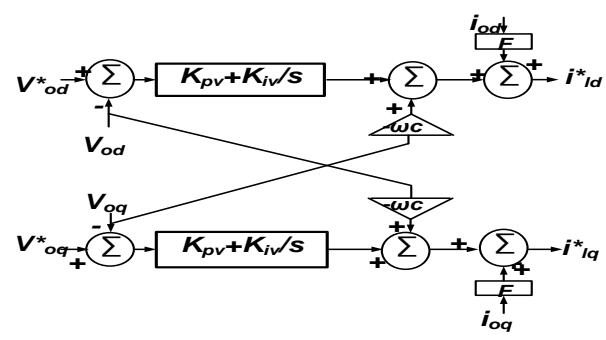

Fig. 4 Voltage controller 


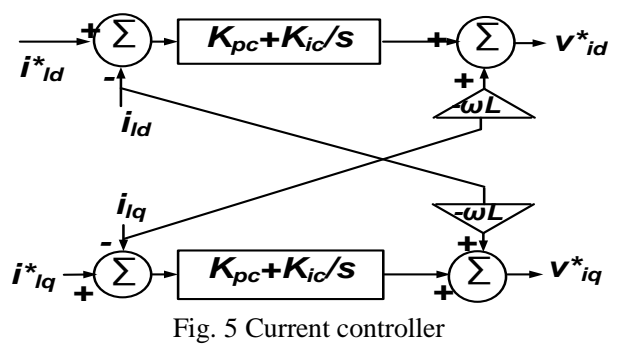

\section{E. Lines Model}

The state equations of line current of $i^{\text {th }}$ line connected between nodes $j$ and $k$ can be described as follows:

$$
\begin{aligned}
& \dot{\boldsymbol{l}}_{\text {lineDi }}=-\frac{r_{\text {linei }}}{L_{\text {linei }}} i_{\text {line } D i}+\omega i_{\text {line } Q i}+\frac{1}{L_{\text {linei }}}\left(v_{b D j}-v_{b D k}\right) \\
& \dot{\boldsymbol{l}}_{\text {line } Q i}=-\frac{r_{\text {linei }}}{L_{\text {linei }}} i_{\text {line } Q i}-\omega i_{\text {line } Q i}+\frac{1}{L_{\text {linei }}}\left(v_{b Q j}-v_{b Q k}\right)
\end{aligned}
$$

\section{F. Load Model}

A general RL load is considered. The state equations are given as:

$$
\begin{aligned}
& \dot{i}_{\text {loadDi }}=-\frac{R_{\text {loadi }}}{L_{\text {loadi }}} i_{\text {loadDi }}+\omega i_{\text {loadQ } i}+\frac{1}{L_{\text {loadi }}} v_{b D i} \\
& \dot{i}_{\text {load } Q i}=-\frac{R_{\text {loadi }}}{L_{\text {loadi }}} i_{\text {load } Q i}-\omega i_{\text {load } D i}+\frac{1}{L_{\text {loadi }}} v_{b Q i}
\end{aligned}
$$

while the load voltages are given as:

$$
\begin{gathered}
\dot{v}_{b D i}=\omega v_{b Q i}+\frac{1}{C_{f}}\left(i_{o D i}-i_{\text {load } i} \pm i_{\text {lineDi }, j}\right) \\
\dot{v}_{b Q i}=-\omega v_{b D i}+\frac{1}{C_{f}}\left(i_{o Q i}-i_{\text {load } Q i} \pm i_{\text {line } Q, j}\right)
\end{gathered}
$$

\section{Proposed Control Technique}

The conventional droop controller performance can be enhanced by adding transient droop terms [21]. The power-sharing coefficients are mainly the dominant lowfrequency modes. So the power sharing controllability will be increased by adding a derivative-integral term in the power controller. The modified droop controllers are given by:

$$
\begin{array}{lc}
\omega=\omega_{n}-m_{p} P_{c}-m_{d} \frac{d P}{d t} \quad, & \dot{\theta}=\omega \\
v_{o d}^{*}=V_{n}-n_{q} Q_{c}-n_{d} \frac{d Q}{d t} & ,
\end{array}
$$

where $m_{d}$ and $n_{d}$ are the transient droop parameters.

The proposed control scheme is suitable to modify the transient response by controlling the transient droop parameters. In fact, the transient droop parameters have to be selected carefully to assure good transient response. To improve the power sharing dynamics performance, an optimization technique is proposed in this paper. The problem is designed to obtain the optimum derivativeintegral parameters $m_{d}$ and $n_{d}$ behind the original droop gains to improve the microgrid stability after getting disturbances.

\section{Particle Swarm Optimization}

Particle swarm optimization (PSO) is a population based stochastic optimization technique developed by Eberhart and Kennedy [23] in 1995, inspired by social behavior of bird flocking or fish schooling. Starting randomly inside the population, the technique is searching for the best candidate solution. Then the optimum values will be obtained by updating the generations. Following the optimum particles, the particles change their position. Starting anywhere in the search space, the algorithm ensures the convergence to the optimal solution. The steps of PSO technique, the basic elements as well as advantages are stated briefly in [7]. The best particle position $\left(p_{\text {best }}\right)$ indicates the position related to the lowest objective function value (highest fitness value) for this particle. The technique will memorize the best position of the all particles. Then the global best position $\left(g_{\text {best }}\right)$ will be the best value of these values. The new position of each particle at iteration $n+1$ is determined as given:

$$
x_{n+1}^{i}=x_{n}^{i}+v_{n+1}^{i}
$$

where $x_{n+1}^{i}$ is the position of particle $i$ at iteration $n+1$; and $v_{n+1}^{i}$ is the corresponding velocity vector.

At each time step, depending on the distance between the personal and global best positions and the current velocity, the particle modifies its velocity as follows:

$$
v_{n+1}^{i}=w v_{n}^{i}+c_{1} r_{1} p_{\text {best }}-x_{n}^{i}+c_{2} r_{2}\left(g_{\text {best }}-x_{n}^{i}\right)
$$

where $w$ is the inertia weight;

$r_{1}$ and $r_{2}$ are random numbers between 0 and 1 ;

$p_{\text {best }}$ is the best position found by particle $i$;

$g_{\text {best }}$ is the best position in the swarm at time $n$; and $c_{1}$ and $c_{2}$ are the "trust" parameters.

The computational flow of the proposed PSO technique is shown in Fig. 6.

\section{Results and Discussion}

\section{A. System Description}

A $220 \mathrm{~V}$ (per phase RMS), $50 \mathrm{~Hz}$ prototype microgrid was built. The test system consists of three equal rating inverters (10KVA) with two load banks of $5.8 \mathrm{~kW}$ at bus 1 and $7.3 \mathrm{~kW}$ at bus 3 . The complete layout is shown in Fig. 7 and the system parameters are summarized in Table I. Each DG unit is represented by a dc voltage source, a VSI, a series LC filter, and coupling inductance $L_{c}$. A complete microgrid test model has been obtained using the procedure explained in Section II. A MATLAB code is used to simulate the given studies. First, a general power flow program is used to obtain the microgrid steady-state conditions. Then step power change, and fault disturbances have been used to verify the microgrid stability.

The paper objective is to investigate the microgrid stability using the optimized droop coefficients and controller gains. So the PI current and voltage controller gains and the power sharing coefficients are obtained using the PSO to achieve the microgrid stability. 
Table I. Test System Parameters

\begin{tabular}{|c|c|c|c|}
\hline \multicolumn{4}{|c|}{ Inverter parameters (10KVA rating) } \\
\hline Parameter & Value & Parameter & Value \\
\hline$f_{s}$ & $8 \mathrm{kHz}$ & $\omega_{c}$ & 31.41 \\
\hline$L_{f}$ & $1.35 \mathrm{mH}$ & $r_{c}$ & $0.03 \Omega$ \\
\hline$C_{f}$ & $50 \mu \mathrm{F}$ & $L_{c}$ & $0.35 \mathrm{mH}$ \\
\hline$r_{f}$ & $0.1 \Omega$ & \multicolumn{2}{|}{} \\
\cline { 1 - 2 }
\end{tabular}

\section{B. Simulation with fault occurred at load}

The fault disturbance was occurred at load1. Figs. 8-11 show the state variables response of the three inverters. After getting this disturbance, the system is stable.

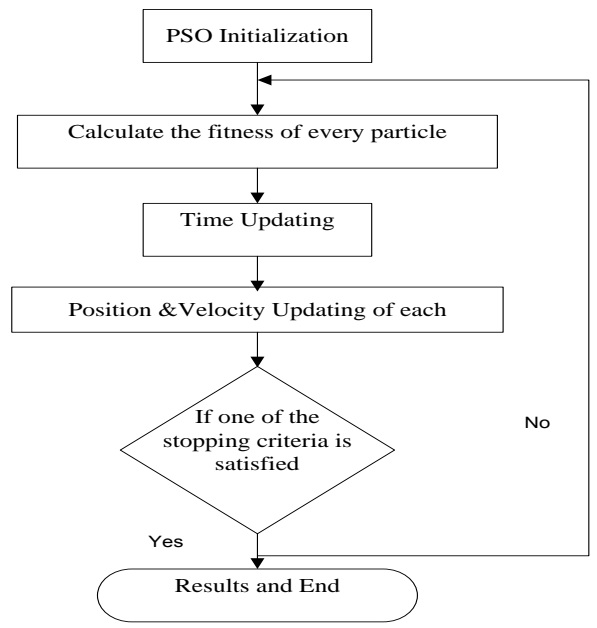

Fig. 6. Computational flow of the proposed PSO

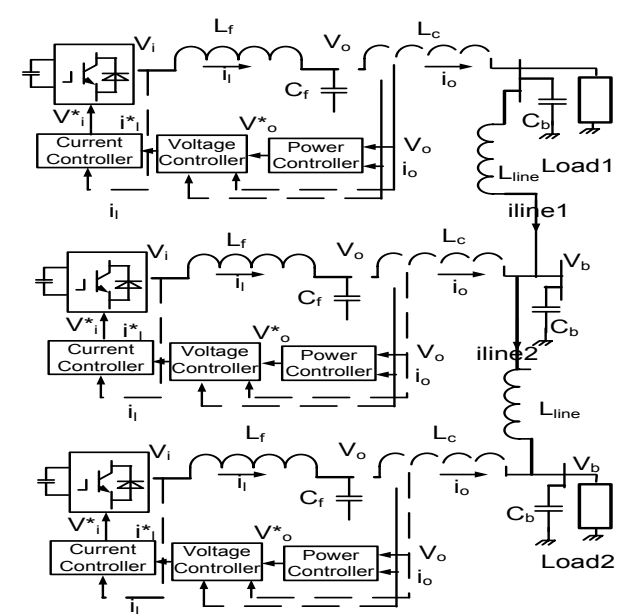

Fig. 7. Autonomous microgrid

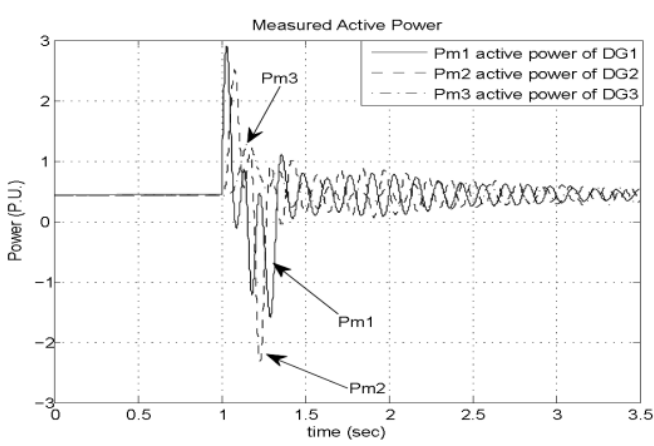

Fig. 8. Response of the output active power response when the fault ocurrs at load1

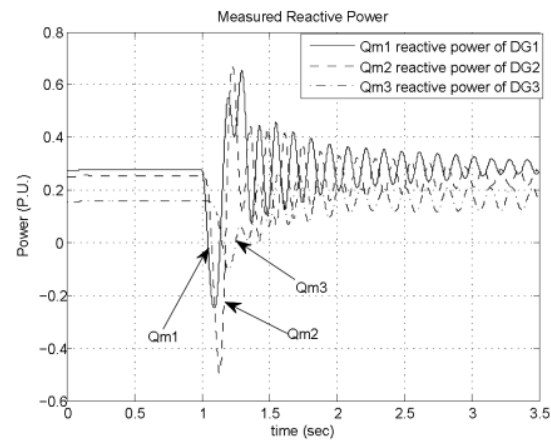

Fig. 9. Response of the output reactive power

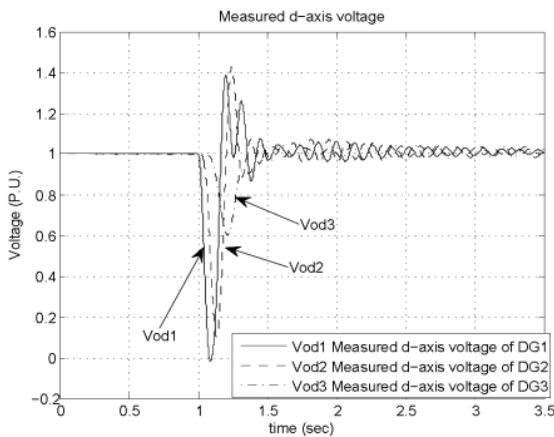

Fig. 10. Response of the output voltage (d-axis)

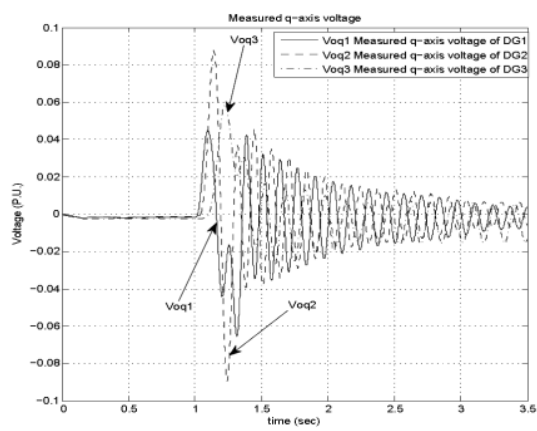

Fig. 11 Response of the output voltage (q-axis)

\section{Simulation with step change in load}

A step load change was conducted at bus1 to investigate the low frequency mode response. In this step change, the load has been changed from initially no load to a load of $3.8 \mathrm{~kW}$. DG output responses of the active, reactive power and voltage for this step change in DG1 are shown in Figs. 12-14. Finally, the capability of the optimal controller has been investigated when the microgrid lost one DG. Using the optimal parameters obtained before, the controller capability is investigated and the microgrid stability is assessed. Figs. 15-17 show the microgrid response when the microgrid lost DG1 using the optimal parameters. As shown in results, the microgrid response is stable after losing one DG. 


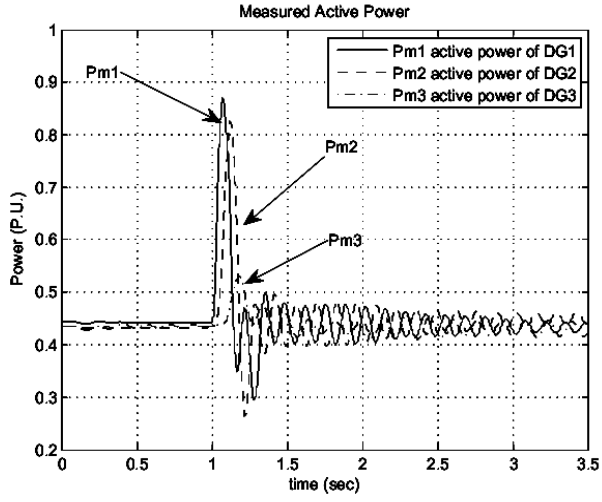

Fig. 12. Response of the output active power when the step response ocurrs at DG1

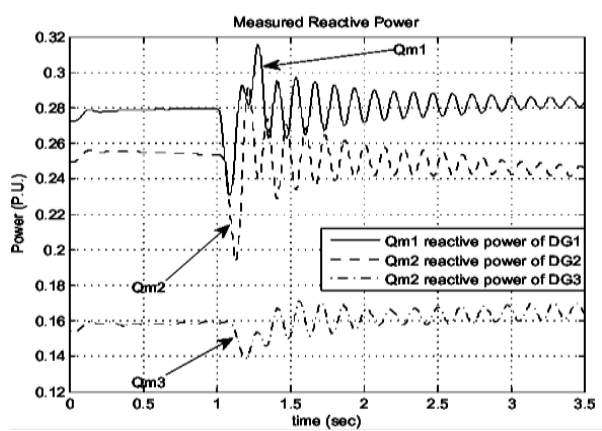

Fig. 13. Response of the output reactive power

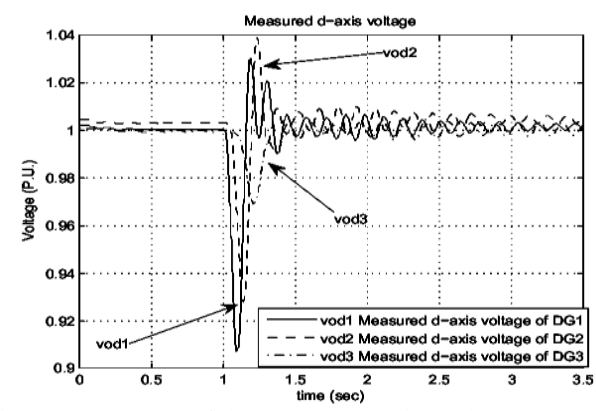

Fig. 14. Response of the output (D-axis) voltage response

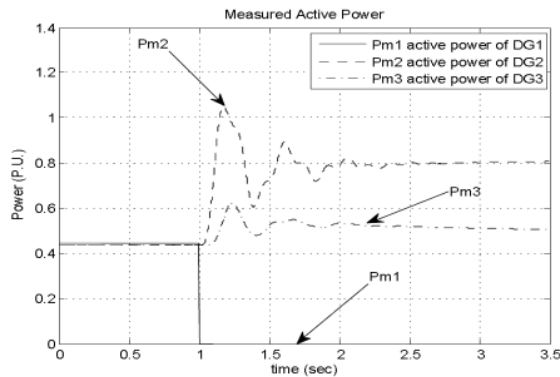

Fig. 15. Response of the output active power of the three DGs when the DG1 has been lost

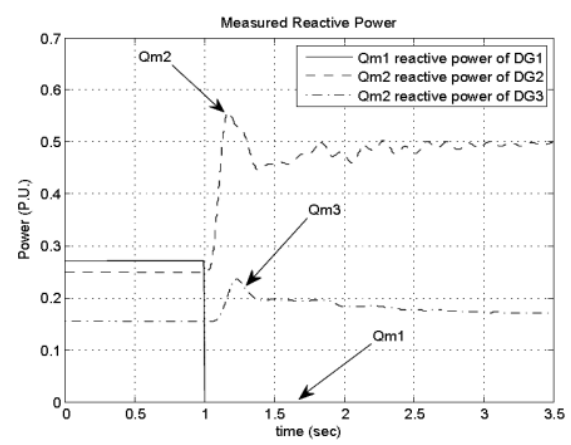

Fig. 16. Response of the output reactive power

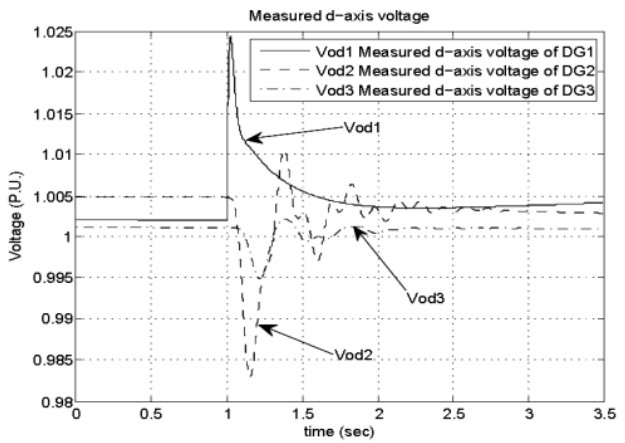

Fig. 17. Response of the output voltage (d-axis)

\section{Conclusion}

In this paper, modified droop control strategy is presented to improve the performance of the existing droop method. A novel scheme is proposed to obtain these droop coefficients to improve the transient response of inverterbased DGs of the autonomous microgrid. The microgrid stability has been verified using a step change and fault disturbances. A simple structured tuning methodology was investigated to optimally tune the proposed power sharing coefficients with the added supplemental transient droop coefficients. The problem has been formulated as a constrained optimization problem where PSO technique was used to solve this problem as an evolutionary search algorithm. It can be concluded from the given results that the PSO technique is very useful for obtaining the optimal PI controllers and power sharing coefficients to achieve sufficient microgrid stability after getting disturbances.

\section{Acknowledgment}

The authors acknowledge the support provided by the Deanship of Scientific Research, King Fahd University of Petroleum \& Minerals, through Electrical Power and Energy Systems Research Group project \# RG1207-1\&2.

\section{References}

[1] J. Guerrero, F. Blaabjerg, T. Zhelev, K. Hemmes, E. Monmasson, S. Jemei, M. Comech, R. Granadino, and J. Frau, "Distributed Generation: Toward a New Energy Paradigm," IEEE Ind. Electron. Mag., vol. 4, no. 1, pp. 52-64, Mar. 2010.

[2] N. Hatziargyriou, H. Asano, R. Iravani, and C. Marnay, "Microgrids," IEEE Power Energy Mag., vol. 5, no. 4, pp. 78-94, Jul./Aug. 2007.

[3] J. Carrasco, L. Franquelo, J. Bialasiewicz, E. Galvan, R. Guisado, M. Prats, J. Leon, and N. Moreno-Alfonso, "Power electronic systems for the grid integration of renewable energy sources: A survey," IEEE Trans. Power Electron., vol. 53, no. 4, pp. 1002 1016, Aug. 2006.

[4] S. Chowdhury, S. P. Chowdhury, and P. Crossley, Microgrids and Active Distribution Networks. Institution of Engineering and Technology, 2009

[5] H. Farhangi, "The path of the smart grid," IEEE Power and Energ. Mag., vol. 8, no. 1, pp. 18-28, Jan.-Feb. 2010.

[6] B. Kroposki, R. Lasseter, T. Ise, S. Morozumi, S. Papatlianassiou, and N. Hatziargyriou, "Making microgrids work," IEEE Power Energy Mag., vol. 6, no. 3, pp. 40-53, May/Jun. 2008.

[7] M. Hassan and M. Abido, "Optimal design of microgrids in autonomous and grid-connected modes using particle swarm 
optimization," IEEE Transactions on Power Electronics, vol.26, no.3, pp. 755-769, Nov. 2010.

[8] A. Mehrizi-Sani, and R. Iravani, "Potential-function based control of a microgrid in islanded and grid-connected modes," IEEE Trans. on Power Systems, vol. 25, no. 4, pp. 1883-1891, Nov. 2010.

[9] A. Seon-Ju, P. Jin-Woo, C. Il-Yop, M. Seung-Il, K. Sang-Hee, and N. SoonRyul, "Power-sharing method of multiple distributed generators considering control modes and configurations of a microgrid," IEEE Trans. Power Del., vol. 25, pp. 2007-2016, 2010.

[10] G. Diaz, C. Gonzalez-Moran, J. Gomez-Aleixandre, and A. Diez, "Scheduling of droop coefficients for frequency and voltage regulation in isolated microgrids," IEEE Trans. Power Syst., vol. 25, no. 1, pp. 489- 496, Feb. 2010.

[11] N. Pogaku, M. Prodanovic' and T. Green, "Modeling analysis and testing of autonomous operation of an inverter-based microgrid," IEEE Transactions on Power Electronics, vol. 22, no.2, pp. 613624, March 2007.

[12] K. Sao, and P. W. Lehn, "Control and power management of converter fed microgrids," IEEE Trans. on Power Systems, Vol. 23, No. 3, pp1088 - 1098, Aug. 2008.

[13] R. Majumder, A. Ghosh, G. Ledwich and F. Zare, "Enhancing the stability of an autonomous microgrid using DSTATCOM," International Journal of Emerging Electric Power Systems vol. 10, Issue 52009.

[14] Y. Li and Y. Li, "Decoupled power control for an inverter based low voltage microgrid in autonomous operation," in Conf. Rec. IEEE International Power Electronics and Motion Control Conference (IPEMC'09), Wuhan China, pp. 2490-2496, 2009.

[15] C. Lee, C. Chuang, C. Chu and P. Chen, "Control strategies for distributed energy resources interface converters in the low voltage microgrid," Proc. IEEE ECCE, pp.2022-2029, 2009.

[16] Q. Zhong, "Robust Droop controller for accurate proportional load sharing among inverters operated in parallel," IEEE Trans. on Industrial Electronics, vol.60, no.4, pp. 1281-1290, 2013.

[17] C. Lee, C. Chu, and P. Cheng, "A new droop control method for the autonomous operation of distributed energy resource interface converters" in Energy Conversion Congress and Exposition (ECCE), IEEE, pp. 702 - 709, Sept. 2010.

[18] Y. Li and Y.W. Li, "Power management of inverter interfaced autonomous microgrid based on virtual frequency-voltage frame," IEEE Trans. Smart Grid., vol. 2, no. 1, pp. 30-40, Mar. 2011.

[19] J. He, and Y. Li, "An enhanced microgrid load demand sharing strategy" IEEE Transactions on Power Electronics, vol. 27, no. 9, Sept. 2012.

[20] R. Majumder, B. Chaudhuri, A. Ghosh, R. Majumder, G. Ledwich and F. Zare, "Improvement of stability and load sharing in an autonomous microgrid using supplementary droop control loop," IEEE Transactions on Power Systems, vol. 25, no. 2, pp. 796-808, May 2010

[21] J. Guerrero, L. de Vicuna, J. Matas, M. Castilla, and J. Miret, “A wireless controller to enhance dynamic performance of parallel inverters in distributed generation system," IEEE Trans. Power Electron., vol. 19, no. 5, pp. 1205-1213, Sep. 2004.

[22] M. A. Hassan and M. A. Abido, "Optimal autonomous control of an inverter-based microgrid using particle swarm optimization," Proceedings of the IEEE International Symposium on Industrial Electronics (ISIE-2010), Bari, Italy, July 4 - 7, pp. 2247-2252, 2010.

[23] Kennedy, "The particle swarm: Social adaptation of knowledge," in Proc. IEEE Int. Conf. Evolutionary Comput., Indianapolis, IN, 1997, pp. 303-308. 